\title{
PSICOLOGIA SOCIAL: UMA ESPECIALIDADE DA PSICOLOGIA?
}

\author{
Cornelis Johannes van Stralen \\ Universidade Federal de Minas Gerais
}

RESUMO: Este artigo questiona a decisão do Conselho Federal de Psicologia de reconhecer a Psicologia Social como especialidade da Psicologia. Esta decisão foi uma resposta a reivindicações de psicólogos que, atuando no campo das políticas públicas, têm procurado uma identidade profissional própria. Ignora, porém, que a Psicologia Social constitui uma disciplina científica específica no campo das ciências sociais, à medida que articula níveis de explicação psicológicos e sociológicos. Argumento que a decisão se tornou possível, de um lado, pela dificuldade de a Psicologia Social construir um campo profissional próprio e, de outro lado, pela posição ambígua que a Associação Brasileira de Psicologia Social tomou diante deste assunto. Concluo que o reconhecimento da Psicologia Social como especialidade da Psicologia poderá fortalecer a tendência de a Psicologia Social se tornar apenas uma disciplina básica no currículo da psicologia, em vez de uma disciplina autônoma que contribua para a compreensão de fenômenos coletivos.

PALAVRAS-CHAVE: Psicologia Social como profissão, especialidades psicológicas, profissionalização, Resolução CPF N $5 / 2003$.

\section{SOCIAL PSYCHOLOGY: A SPECIALTY WITHIN PSYCHOLOGY?}

ABSTRACT: This article questions the decision of the Conselho Federal de Psicologia to recognise Social Psychology as a specialty within Psychology. This decision was an answer to the psychologists' claims working in the field of Public Politcs and serching for their own professional identity. However, the study ignores that Social Psychology is a specific scientific subject in the field of Social Sciences as it connects psychological and sociological levels of explanation. My argument is that this decision became possible partly because of the difficulties encountered by Social Psychology in forming its own professional field, and partly because of the ambiguos attitude taken by the Associação Brasileira de Psicologia Social approaching this issue. It's possible to conclude that the recognition of Social Psychology as a specialty in Psychology may be able to strengthen the tendency of Social Psychology to become only a basic subject in Psychology, instead of transforming it into an autonomous subject that contributes to the comprehension of collective phenomena.

KEY WORDS: Social Psychology as profession, psychological specialties, professionalization, resolution CPF N $5 / 2003$.

Em junho de 2003, o Conselho Federal de Psicologia-CFP editou a Resolução No 5/2003 que reconhece a Psicologia Social como especialidade da Psicologia. Esse reconhecimento causa estranheza, pois a Psicologia Social, como espaço de interseção entre a Psicologia e a Sociologia, não se restringe ao campo da Psicologia. Como tal, a sua prática profissional não coincide com a prática profissional da Psicologia e, portanto, não deverá estar sujeita à ação reguladora do CFP.

O reconhecimento da Psicologia Social como especialidade da Psicologia aparentemente é resultado dos esforços do CFP para ampliar o campo profissional da psicologia. Trata-se de uma ação legítima num contexto marcado pelo grande crescimento do número de psicólogos em face de uma definição muito restrita do campo profissional pela lei que regula- menta a profissão do psicólogo (Lei 4.119 de 27/8/

1962). Esta lei define, no seu artigo 13:

"Ao portador do diploma de psicólogo é conferido o direito de ensinar Psicologia nos vários cursos de que trata esta lei, observadas as exigências legais específicas, e a exercer a profissão de Psicólogo.

$\S 1^{\circ}$ - Constitui função privativa do Psicólogo a utilização de métodos e técnicas psicológicas com os seguintes objetivos:
a) diagnóstico psicológico;
b) orientação e seleção profissional;
c) orientação psicopedagógica;
$\S 2^{\circ}$ - É da competência do Psicólogo a colaboração em assuntos psicológicos 
ligados a outras ciências (Brasil, 1962).

Há de se observar que, ao instituir em 2000 o título de especialista em Psicologia (Resolução CFP $\mathrm{N}^{\circ} 14 / 00$ de $20 / 12 / 2000$ ), o CFP se restringiu a especialidades que grosso modo já se enquadravam no campo profissional da psicologia: Psicologia Escolar / Educacional, Psicologia Organizacional e do Trabalho, Psicologia do Trânsito, Psicologia Jurídica, Psicologia do Esporte, Psicologia Hospitalar, Psicologia Clínica, Psicopedagogia, e Psicomotricidade. Entretanto, ao reconhecer a Psicologia Social como especialidade da Psicologia, o CFP foi estendendo sua competência reguladora para um campo interdisciplinar, ou seja, para além dos limites da psicologia.

A atual diretoria da Associação Brasileira de Psicologia Social - ABRAPSO vem questionando essa tomada de posição do CFP. Entretanto, a despeito da falta de legalidade, a resolução não deixa de possuir certa legitimidade, considerando:

1. a demanda de vários psicólogos, inscritos nos Conselhos de Psicologia, pela regulamentação de suas atividades no campo social como especialidade; e

2. a tendência de considerar a Psicologia Social um ramo da Psicologia.

Para esclarecer a contradição entre o posicionamento da atual diretoria da ABRAPSO e a aparente legitimidade da resolução, torna-se necessário discutir o status da Psicologia Social como disciplina científica e como campo profissional.

\section{A PSICOLOGIA SOCIAL COMO DISCIPLINA CIENTÍFICA}

Atualmente, há bastante consenso de que a Psicologia Social como disciplina científica possui uma especificidade, não pelo seu objeto de estudo, mas antes de tudo por suas abordagens teóricas que articulam aspectos estruturais e aspectos subjetivos e integram explicações psicológicas e sociológicas. Como tal, a Psicologia Social apresenta-se como um campo de interseção entre a Psicologia e a sociologia, no qual encontramos teorias procedentes tanto da Psicologia como da sociologia. Esta especificidade da Psicologia Social causa uma tensão interna à disciplina, entre o que se convencionou chamar Psicologia Social psicológica e Psicologia Social sociológica.

Num primeiro momento, a Psicologia Social sociológica estava mais em evidência, o que se expressou, entre outros, no maior número de manuais de Psicologia Social escritos ou organizados por sociólogos (ALVARO \& GARRIDO, 2003:7). Esta tendência se foi invertendo, levando a uma situação em que a maioria dos psicólogos sociais se forma em cursos de Psicologia e na qual a Psicologia Social psicológi- ca se tornou hegemônica em detrimento das contribuições de autores, tais como Simmel, Goffman, Mead, Schutz, Elias, Giddens, Bourdieu, etc. Atualmente, há uma tendência contrária à hegemonia da Psicologia Social psicológica que se esforça para reincorporar contribuições da Sociologia e se pauta por um compromisso ético-político voltado para questões sociais. Apesar disso, a identificação da Psicologia Social como um ramo da Psicologia não apenas continua forte, mas entre nós está crescendo.

Alvaro e Garrido sugerem que, de certa maneira, o próprio rótulo de Psicologia Social tem contribuído para esta identificação (2003:6). Entretanto, parece-nos que a retração da Psicologia Social para dentro do campo da Psicologia tem sido influenciada por uma série de outros fatores. Aqui podemos apontar a retração de abordagens estruturalistas nas ciências sociais e a crescente preocupação, por parte de sociólogos, cientistas políticos e outros cientistas sociais, com a dimensão subjetiva de fenômenos sociais e políticos. Se isso tem ampliado a produção de conhecimentos psicossociais no campo das Ciências Humanas e Ciências Sociais Aplicadas, de outro lado tem levado à diminuição do número de disciplinas da Psicologia Social ofertadas nos diversos cursos da área das Ciências Humanas e Ciências Sociais Aplicadas e à redução da visibilidade da Psicologia Social como campo de interseção entre a Psicologia e a Sociologia, favorecendo a identificação da Psicologia Social com a Psicologia. Esta situação tem como conseqüência o fato de que o número de psicólogos sociais com formação em sociologia tem caído drasticamente. A ação reguladora do CFP também contribui para este fenômeno, entre outros fatores por dificultar a contratação, pelas universidades, de psicólogos sociais sem formação em psicologia, ao estipular que o supervisor de estágios de alunos de Psicologia deverá ser psicólogo inscrito no Conselho de Psicologia.

Fator agravante para a formação de psicólogos sociais é ainda a situação marginal da Psicologia Social dentro dos cursos da Psicologia. A maioria dos cursos continua sendo marcada por uma estrutura curricular tradicional em que nos primeiros períodos predomina o ensino de processos psicológicos básicos com grande presença da psicologia experimental e nos últimos períodos o ensino de práticas da psicologia clínica. Neste contexto, a Psicologia Social em geral aparece apenas como uma disciplina básica que permite compreender os aspectos sociais do comportamento psicológico. Esta situação é apenas parcialmente corrigida pelos programas de pós-graduação em Psicologia Social ou por outros programas com uma área de concentração em Psicologia Social, pois é notório que parte dos alunos que procuram estes programas, está mais interessada em 
aprofundar o estudo de aspectos sociais de determinados fenômenos do que em uma formação para psicólogo social.

\section{A PSICOLOGIA SOCIAL}

\section{COMO CAMPO PROFISSIONAL}

Diante de profissões, tais como a de clérigos, de médicos e de especialistas em direito, a profissão de psicólogos é recente. Enquanto estes antecedem a sociedade capitalista, a de psicólogos surgiu no bojo do processo da divisão de trabalho que marca as sociedades modernas (veja DURKHEIM, 1984). Há de ressaltar que a exigência de novas competências e habilidades no trabalho ou a fragmentação cada vez maior do processo de produção não é condição suficiente para a emergência de novas profissões. Em contraste com as ocupações, para as profissões o domínio de conhecimentos complexos, organizados e sistematizados e de difícil acesso para não-profissionais funciona como base técnica da autoridade profissional.

Profissões se caracterizam por uma assimetria de competências: o cliente tem que confiar no saber do profissional e o profissional, por sua vez, tem que respeitar o cliente. Esta relação é garantida por formas institucionais: formação padronizada, conselhos profissionais, credenciamentos, códigos de ética, etc. O elemento constitutivo de uma profissão é, antes de tudo, a aplicação de conhecimentos relativamente abstratos a problemas particulares. Nesta perspectiva, o fenômeno central da vida profissional é, de acordo com Abbott (1988), o vínculo entre a profissão e suas tarefas. Este vínculo constitui uma jurisdição que se fundamenta em conhecimentos e é ancorada por instituições sociais formais e informais. A jurisdição não é algo estável, mas, ao longo do tempo, ocorre a incorporação de novas tarefas e perda de outras, num contexto de desenvolvimento científico e tecnológico, de mudança social e de lutas pelo poder entre profissionais. Neste processo, as relações entre as profissões e dentro delas modificam pelo surgimento de novos conhecimentos, pela aplicação de conhecimentos em novos problemas e pela crescente complexidade das tarefas. Emergem novas jurisdições que se materializam em especialidades, novas profissões ou em fusões e divisões de profissões existentes.

Profissões tais como psicólogo ou sociólogo carecem ainda de consolidação. Não há vínculos fortes entre a profissão e determinadas tarefas, pois tanto a Psicologia como a Sociologia são marcadas por uma diversidade de abordagens teóricas e padecem de um sistema de conhecimentos sistematizados e universalizados. Entretanto, a Psicologia procura avançar no processo de profissionalização, organizando treinamentos específicos para áreas de aplicação, re- gulamentando especialidades e produzindo conhecimentos mais exclusivos para determinadas tarefas. Este processo vem sendo marcado por algumas tendências:

1. a jurisdição definida pela lei que regulamenta a profissão de psicólogo é mais restrita do que o sistema de conhecimentos teóricos e práticos, o que mobiliza a profissão pela incorporação de novas tarefas na sua jurisdição (políticas expansionistas);

2. a psicoterapia disputada com a medicina (psiquiatria) foi gradualmente incorporada na jurisdição da psicologia, o que foi favorecido por dois fatores: o fato de que a psiquiatria ignora, muitas vezes, problemas menores de saúde mental que são, sim, abordados por psicólogos e o grande número de psicólogos versus o número reduzido de psiquiatras. Esta área, entretanto, chega a ser área disputada por outras profissões e agentes sociais (serviço social, práticas alternativas, etc.);

3. o processo de especialização avança mais pela diferenciação da clientela (Psicologia Hospitalar, Psicologia do Esporte, Psicologia Escolar, etc.), do que pela diferenciação de conhecimentos, ainda que a instituição do título de especialista tenha sido justificada pelos "avanços da Ciência Psicológica, os quais têm propiciado a emergência de áreas de conhecimento específico para a atuação do profissional de Psicologia" (Resolução CFP, N¹4/00); e

4. o processo de especialização vem sendo marcado por uma hierarquização de tarefas, em que a Psicologia Clínica ganha maior status na base de conhecimentos mais exclusivos que articulam saberes teóricos e práticos. Isso não apenas favorece a reprodução da estrutura tradicional de cursos de Psicologia, mas também diminui o status social de outras práticas da Psicologia.

Para a Psicologia Social, o estabelecimento de um vínculo entre profissão e tarefas, baseado no domínio de um sistema de conhecimentos específicos, tem sido difícil por ela representar uma interseção entre a sociologia e a psicologia. Nesta situação, prevalece a tendência de o psicólogo social se manter incluído na categoria profissional relativamente mais forte: a da psicologia. Timidamente, têm sido feitos alguns esforços para criar especialidades de acordo com o contexto de trabalho ou com a clientela, psicólogos sociais se denominando analistas institucionais, especialistas em dinâmica de grupo, psicodramatistas, psicólogos de trabalho, etc., mas estes esforços em geral não se consolidaram.

A situação modificou-se com o surgimento de novas tarefas, principalmente em programas sociais e educacionais, nos quais tanto psicólogos (sociais) como outros profissionais (assistentes sociais, sociólogos, pedagogos, etc) têm-se inseridos. Estas tarefas 
compartilhadas com outras profissões tendem a promover uma perda de trocabilidade de psicólogos profissionais entre si e uma pressão pela especialização, ao lado da competição com os outros profissionais.

A pressão por especialização não tem levado a um afastamento de psicólogos sociais dos profissionais da psicologia. Esta separação implicaria a união com os outros profissionais que atuam nos programas sociais e educacionais, realizando as mesmas tarefas. Entretanto, o fato de estas outras profissões serem ainda menos consolidadas do que a psicologia, faz com que prevaleça a tendência de não se abandonar o guarda-chuva protetor da Psicologia e que surja a demanda de especialização dentro da profissão de psicólogo, seja como Psicologia Social, seja como Psicologia Comunitária. De acordo com o CFP, esta demanda já estava presente quando foi instituído o título profissional de Especialista em Psicologia e quando foram definidas as diversas especialidades (Resolução CPF N ${ }^{\circ} 14 / 00$ ).

Um eventual reconhecimento da Psicologia Comunitária como especialidade em Psicologia não se concretizou, devido à forte resistência de setores vinculados a esta área. Esta resistência, entretanto, não se verificou no caso do reconhecimento da Psicologia Social como especialidade da Psicologia, tendo em vista a ambigüidade com que a ABRAPSO tratou esta questão. Esta ambigüidade está relacionada com os objetivos da entidade que não distinguem claramente a Psicologia Social de uma Psicologia Socialmente comprometida.

Quando a ABRAPSO foi criada em 1980, pretendia constituir-se, ao mesmo tempo:

[...] uma entidade que congregue não somente psicólogos de diferentes áreas, mas também outros cientistas sociais que estejam interessados no desenvolvimento da Psicologia Social no Brasil"e "uma associação que se proponha a incentivar o desenvolvimento da Psicologia voltada para a nossa própria realidade social (ABRAPSO, 1980).

Esta ambigüidade reproduz-se no atual Estatuto da ABRAPSO, no qual se formulam as seguintes finalidades:

1. garantir e desenvolver as relações entre pessoas dedicadas ao estudo, ensino, investigação e aplicação da Psicologia em uma perspectiva social no Brasil;.

2. propiciar a difusão e o intercâmbio de informações sobre o desenvolvimento do conhecimento e prática da Psicologia Social;

3. organizar conferências e cursos e promover a publicação de trabalhos de in- teresse para o desenvolvimento da Psicologia Social;

4. promover a integração da Psicologia com outras áreas do conhecimento que atuem em uma perspectiva social crítica; e

5. incentivar e apoiar institucionalmente o desenvolvimento de ações no campo social e comunitária".

A natureza ambígua da ABRAPSO tem sido estratégica em termos políticos, pois ajuda a promover a idéia de que o compromisso social e político que tem caracterizado a Psicologia Social no Brasil, a partir dos anos 70, deve ser compartilhado pela Psicologia. Entretanto, ela dificulta o debate sobre a especificidade da Psicologia Social e faz com que, não raras vezes, a Psicologia Social seja confundida com uma psicologia crítica ou politicamente engajada. Nesta perspectiva é significativo que, ao se opor ao reconhecimento da Psicologia Social como especialidade da Psicologia, a então diretoria da ABRAPSO não fez referência à especificidade da Psicologia Social, como atesta carta dirigida ao CFP:

A proposta de uma Especialidade em Psicologia Social não é coerente com a finalidade e a composição desta Associação, e, ainda, vem de encontro aos auspícios da luta pela compreensão de que todo a Psicologia é social, pois "Esta afirmação não significa reduzir as áreas específicas da Psicologia à Psicologia Social, mas sim cada uma assumir dentro de sua especialidade a natureza histórico-social do ser humano"(Lane, Silvia T.M. A Psicologia Social e uma nova concepção do homem para a Psicologia. In: Lane, Silvia T.M. e Codo, W (org.) Psicologia Social: o homem em movimento. São Paulo: Brasiliense, 1984, p. 19).

A posição desta direção é de não legitimar uma ação que venha depor ao contrário desta luta e, também, não contribuir para a formação de uma especialidade em Psicologia Social, correndo o risco de delimitar o compromisso éticosócio-político que se quer para a prática de qualquer profissional como um fazer técnico somente dos profissionais especialistas nesta área (ABRAPSO,2002).

Se para ABRAPSO a especificidade da Psicologia Social não constituía argumento, esta sim orientava a resolução do CFP. Tomando como referência o avanço da Psicologia e a consolidação da área profissional da Psicologia Social, esta define a especiali- 
dade de Psicologia Social, da seguinte forma: A especialidade de Psicologia Social fica instituída com a seguinte definição: I Atua fundamentada na compreensão da dimensão subjetiva dos fenômenos sociais e coletivos, sob diferentes enfoques teóricos e metodológicos, com o objetivo de problematizar e propor ações no âmbito social. O psicólogo, nesse campo, desenvolve atividades em diferentes espaços institucionais e comunitários, no âmbito da Saúde, Educação, trabalho, lazer, meio ambiente, comunicação social, justiça, segurança e assistência social. Seu trabalho envolve proposições de políticas e ações relacionadas à comunidade em geral e aos movimentos sociais de grupos étnico-raciais, religiosos, de gênero, geracionais, de orientação sexual, de classes sociais e de outros segmentos socioculturais, com vistas à realização de projetos da área social e/ou definição de políticas públicas. Realiza estudo, pesquisa e supervisão sobre temas pertinentes à relação do indivíduo com a sociedade, com o intuito de promover a problematização e a construção de proposições que qualifiquem o trabalho e a formação no campo da Psicologia Social (Resolução CFP $\mathrm{N}^{\circ}$ 05/2003, art. 3).

Entretanto, não se distingue aqui claramente uma jurisdição nova, pois tratam-se de tarefas compartilhadas com outras profissionais sem vínculo com uma base de conhecimentos especializados, fazendose apenas referência ao avanço da Psicologia (Resolução CFP N 5/2003).

\section{IMPLICAÇÕES DA RESOLUÇÃO 5/2003}

A resolução que institui a Psicologia Social como especialidade da Psicologia não foi apenas resultado da procura de reconhecimento profissional por parte de psicólogos que atuam em programas sociais e educacionais ao lado de outros profissionais. A idealização desta resolução foi favorecida também pelo significado político da Psicologia Social, pois foi esta que, no campo da Psicologia, empenhou-se para construir uma Psicologia voltada para problemas brasileiras e propiciou, numa conjuntura de oposição ao Estado autoritário-burocrático e de transição para um regime democrático, a formulação de uma Psicologia crítica. Entretanto, ela ignora a especificidade da Psicologia Social como disciplina que integra concepções psicológicas e sociológicas e que disso deriva sua capacidade de vincular teoria e práxis e de se tornar um instrumento de transformação social. Esta resolução tende a tornar a Psicologia Social meramente parte do corpus da psicologia, roubando-lhe a sua própria alma. Tende também a reforçar a tendência de a Psicologia Social se tornar apenas uma disciplina básica nos cursos de Psicologia que, ao abordar aspectos sociais do comportamento, transforma-se num capítulo da Psicologia Geral em vez de contribuir para a compreensão do funcionamento da sociedade e da cultura. Acaba, assim, de promover uma Psicologia Social psicológica em detrimento de uma Psicologia Social sociológica.

É por estes motivos que a ABRAPSO atual procura promover um debate sobre esta questão no intuito de repensar a resolução e de promover condições para reconhecer a presença da Psicologia Social no campo das Ciências Humanas e Sociais como uma ciência que aborda fenômenos básicos do funcionamento da sociedade e cultura e possui uma intencionalidade voltada para a transformação social. A Psicologia Social tem uma relação estreita com a Psicologia, mas não coincide com ela.

NOTA

Trabalho apresentado na mesa-redonda "A Psicologia Social como Especialidade" no Encontro da ABRAPSORIO, Rio de Janeiro, UERJ, 16-18/11/2004

\section{REFERÊNCIAS}

ABBOTT, A. The System of Professions: an Essay on the Division of Expert Labor. London/Chicago: The University of Chicago Press, 1988.

ABRAPSO. Estatuto da Associação Brasileira de Psicologia Social. Disponível em:

$<$ www.abrapso.org.br>. Acesso em 28 fev.2005.

ABRAPSO, Ata da reunião para fundação da Associação Brasileira de Psicologia Social -ABRAPSO. In: ABRAPSO, Anais do I Encontro Brasileiro de Psicologia Social. São Paulo, 1980. Mimeografado. pp 9093.

ABRAPSO. Ofício da Presidente da ABRAPSO para o CFP, 05/06/2002. Disponível em:

<www.abrapso.org.br>.Acesso em 28 fev. 2005.

ALVARO, J.L. \& GARRIDO, A. Psicologia Social: Perspectivas Psicológicas y Sociológicas. Mc.Graw Hill: Madrid, 2003.

BRASIL. Lei 4.119, de 27 de Agosto de 1962. Dispõe sobre os cursos de formação em Psicologia e regulamenta a profissão de Psicólogo. Brasília, 1962. 
CONSELHO FEDERAL DE PSICOLOGIA. Resolução n ${ }^{\circ}$. 014/00, de 20 de dezembro de 2000. Institui o título profissional de Especialista em Psicologia e dispõe sobre normas e procedimentos para seu registro. Brasília, 2000.

CONSELHO FEDERAL DE PSICOLOGIA. Resolução $n^{\circ}$. 5/2003, de 14 de junho de 2003. Reconhece a Psicologia Social como especialidade em Psicologia para finalidade de concessão e registro do título de Especialista. Brasília, 2003.

DURKHEIM, C. A Divisão do Trabalho Social. Porto: Editorial Presença, 1984.

Cornelis Johannes van Stralen é psicólogo social com doutorado em sociologia e política.

Coordenador do Programa de Pós-Graduação em

Psicologia da UFMG e Presidente da ABRAPSO

Gestão 2003/2005. O endereço eletrônico do autor é stralen@medicina.ufmg.br

\section{Cornelis Van Stralen \\ Psicologia social: \\ uma especialidade da psicologia? \\ Recebido: 14/03/2005 \\ $1^{\text {a }}$ revisão: 28/05/2005 \\ Aceite final: 2/06/2005}

